\title{
Parę słów wprowadzenia
}

W 1936 roku nieco zapomniany dzisiaj niemiecki myśliciel Arthur Liebert w wydawanym przez siebie na emigracji w Belgradzie piśmie „Philosophia”, na którego łamach trzy lata później ukazała się słynna praca Edmunda Husserla Kryzys nauk europejskich i fenomenologia transcendentalna, opublikował obszerną rozprawę zatytułowaną Das Problem der Kultur und die Kulturkritik unserer Zeit. Liebert, bardzo aktywnie działający w i na rzecz Kant-Gesellschaft, sporo piszący o teorii poznania, kryzysie współczesności i kulturze, acz jako filozof niezbyt oryginalny, w przywoływanym tekście Kantowską kategorię krytyki zinterpretował jako „prafunkcję ludzkiego ducha”. Z tego zaś wynikało dla niego, że „krytyka kultury $\mathrm{w}$ istocie nie jest niczym innym jak filozofią kultury, a filozofia kultury niczym innym jak krytyką kultury" ". Nie sposób pominąc, że sformułowanie to pochodzi z najlepszego dla filozofii kultury — jako oddzielnej subdyscypliny — czasu, który z wielu powodów sprzyjał eksponowaniu jej krytycznej funkcji. Ale jak nie musi ona, a wręcz nie może ograniczać się do pełnienia wyłącznie zadań krytycznych, tak krytyka kultury nie zawsze osiąga poziom filozoficzny. W dawnej, ale wciąż instruktywnej systematyce kierunków filozoficzno-kulturalnej pracy, Wilhelm Peerpet ${ }^{2}$ wydzielał na przykład filozoficzną krytykę kultury, która za swój

1 A. Liebert, Das Problem der Kultur und die Kulturkritik unserer Zeit, „Philosophia” 1936, s. 249. To ujęcie można by zestawić z pochodzącym z owego czasu rozumowaniem Eduarda Sprangera, który w 1930 roku w artykule Zur geistigen Lage der Gegenwart ([w:] idem, Kulturphilosophie und Kulturkritik, Tübingen 1969) tak porządkował działy filozofii kultury: systematyka (bada to, czego przejawem są niepokojące zjawiska), problematyka (jakie zagadnienia pojawiają się w postawie względem przyszłości) i terapia (z jakimi działaniami należy wiązać największe nadzieje). Uwagę zwraca tutaj połączenie zadań poznawczych, oceniających i praktycznych. W kwestii interpretacji kategorii krytyki i kultury u Kanta zob. H.-J. Lachmann, Vernunftkritik und Kulturkritik. Anmerkungen zu Immanuel Kants Kulturbegriffs, cz. 1, „Kulturwissenschaftliche Studien” 2, 1997; cz. 2, 3, 1998.

${ }^{2}$ W. Perpeet, Kulturphilosophie, Bonn 1997. To właściwie osobne wydanie jego klasycznego już artykułu w „Archiv für Begriffsgeschichte” 20, 1976. Gwoli ujęcia tego w dłuższej perspektywie historycznej można polecić książki Davida Sobrevilli, Der Ursprung des Kulturbegriffes, der Kulturphilosophie und der Kulturkritik, Tübingen 1971, oraz Georga Bollenbecka, Eine Geschichte der Kulturkritik. Von Rousseau bis Günther Anders, München 2007. Godne uwagi jest ponadto słownikowe, z obszerną bibliografią, hasło Kulturkritik, autorstwa Hjördisa Beckera w Handbuch Kulturphilosophie (red. R. Konersmann, Stuttgart 2012).

Prace Kulturoznawcze 23, 2019, nr 1

(C) for this edition by CNS 
przedmiot obierała podstawy, motywy i intencje dogmatycznej krytyki kultury. Wcale nie jedynie dla oddania tego, jak się sprawy mają, warto przytoczyć opinie wyrastające z namysłu nad dziejami kategorii kultury i refleksji o niej, że pierwsze oznaki tej drugiej odnajdziemy w wypowiedziach o nastawieniu krytycznym ${ }^{3}$. Wszakże bogate dziedzictwo bywa obciążające i trzeba bardzo uważać, by oddając mu szacunek, nie rozminąc się z aktualnym stanem rzeczy i jego wyzwaniami. Tradycyjne modele krytyki kultury bywają współcześnie uprawiane, lecz przecież zarówno kultura, jak i myśl o niej podlegały wielu przemianom. O ile na przełomie XIX i XX wieku filozofia kultury uzyskiwała samodzielność, dystansując się wobec nauk o kulturze i eksponując swoją funkcję krytyczną, o tyle wiek później sytuację wyznacza najpierw cultural turn, który wkrótce przemienił się w wielość zwrotów, właściwie już tylko ramowo określanych jako kulturowe. Jednym z narzucających staje się zatem pytanie, na czym ma polegać wobec wszystkich tego następstw krytyka kultury. Jak należy argumentować się na jej rzecz, kiedy nie może ani pojmować się sama, ani działać tak jak do niedawna. A jakkolwiek nie nazywać by naszą teraźniejszość - ponowoczesnością, płynną czy drugą nowoczesnością - jest w niej miejsce dla krytyki kultury, a może wręcz wzmaga się jej potrzeba ${ }^{4}$. Nie sposób też zlekceważyć, że część reprezentantów nauk o kulturze czy pewnych w nich orientacji koncentruje swoją działalność na realizacji funkcji krytycznej, choć nazywana bywa niekiedy zgoła inaczej. Najłatwiej oczywiście dostrzec to wśród tych, którzy nawiązują do dziedzictwa szkoły frankfurckiej, choć czasem jest to bardzo zapośredniczone ${ }^{5}$, a mariaże teorii krytycznej i poststrukturalizmu owocowały wieloma interesującymi koncepcjami. Wskazując na oddziaływania idei M. Horkheimera i T.W. Adorno ${ }^{6}$ na choćby $\mathrm{cul}$ tural studies, nie sposób do tego sprowadzić tradycji krytycznej w obrębie nauk społecznych, która ma także odmienne źródła i współczesne postaci ${ }^{7}$.

${ }^{3}$ Zob. H. Schnädelbach, Kultura i krytyka kultury, przeł. K. Krzemieniowa, [w:] idem, Próba rehabilitacji animal rationale, Warszawa 2001. Ponadto H. Böhme, Stufen der Reflexion: Die Kulturwissenschaften in der Kultur, [w:] Handbuch der Kulturwissenschaften, t. 2, red. F. Jaeger, B. Liebsch, Stuttgart-Weimar 2011. W nieco inny sposób potwierdzają to opisy, że oświecenie to okres narodzin zagadnienia kultury, a ukształtowane wtedy wzorce krytyki kultury mają status klasycznych i stanowią nieustanny punkt odniesienia. Tak jest choćby u R. Konersmanna (Krytyka kultury, przeł. K. Krzemienowa, Warszawa 2012).

4 Zob. S. Krzemień-Ojak, O doniostości kultury i o powinności krytyki, [w:] R. Konersmann, Krytyka kultury...

5 Jak to się przedstawia w jednym z odłamów niemieckojęzycznego kulturoznawstwa, pisałem w rozprawie O pewnej krytyce kulturalizmu, „Prace Kulturoznawcze” 20, 2016.

${ }^{6}$ Dzisiejszą ocenę poglądów autora Dialektyki negatywnej przedstawiają T. Maślanka, R. Wiśniewski, Krytyka jest sprawa każdego z nas, czyli o kulturowym mandarynizmie Theodora Adorna, [w:] T.W. Adorno, Przemyst kulturalny, przeł. M. Bucholc. Warszawa 2019. Zob. też J. Momoro, Epistemologia anachronizmu, „Teksty Drugie” 2017, nr 1.

7 Jakkolwiek dawno już wydana, ale wciąż w odniesieniu do aspektu historycznego godna polecenia jest praca Janusza Muchy, Socjologia jako krytyka społeczna, Warszawa 1986. Z kolei syntetycznego wglądu w to, jak myśl krytyczna identyfikuje siebie i swe zdania we współczesnej

Prace Kulturoznawcze 23, 2019, nr 1

(C) for this edition by CNS 
Jak podsumowano w pewnym słownikowym haśle,

o ile nauki o kulturze traktują się jako nauki, o tyle zdane są na krytykę, ale jednak ich pozycja jest szczególna ze względu na to, że ich zakres przedmiotowy stanowią wartości, do których krytyka się odwołuje. Przydaje im to szczególności w systemie dyscyplin, ale zarazem czyni to ich status „niepewnym” (prekär). Sedno jednak tkwi w tym, że owa „niepewność”, narzucająca wprost samorefleksję, staje się źródłem ich siły w tym mianowicie sensie, że staje się ona elementem ich praktyki. Nauki o kulturze przeto uprzywilejowane są do pokazania, że każda nauka jest częścią kultury ${ }^{8}$.

Z podobnego typu myślenia wyrastają także polskie koncepcje kulturoznawstwa krytycznego, a dyskusje, do których one prowokują, dotyczą nie tyle tego, co jest jego przedmiotem, lecz przede wszystkim tego, kim jest sam badacz, jakie ma uprawnienia i zadania, jak odbierany przez tych, o których — koniec konców - pisze. Epistemologia i metodologia ustąpić muszą więcej miejsca kwestiom etycznym i politycznym. W tym stopniu, w jakim okazuje się to gwarantem ważności kulturoznawstwa, bywa to obracane przeciwko niemu samemu. Po raz kolejny krytykowana krytyka musi dowieść swego uprawomocnienia. Ralf Konersmann skłonny jest jednak od krytycznej nawet teorii kultury odróżniać filozofię kultury ${ }^{9}$, dla której zadania krytyczne zachowują pierwszorzędną rangę. Ale forma ich urzeczywistnienia musi być na nowo zdefiniowana. O ile siłą rzeczy dla tego myśliciela koncepcja Adorna jest punktem odniesienia, o tyle jednak odcina się od jego ekskluzywizmu, indywidualizmu oraz traktowania krytyki jako „formy myślenia”, podczas gdy staje się ona „formą życia” i akcją społeczną:

Krytyka aktywistyczna budzi niepokój, ale — nie jak sokratejski Rousseau, z ryzykiem niepewnego wyniku, lecz organizując jednomyślność sympatyków. Jest to ta jednomyślność i indywidualne zobowiązanie wobec ideału (Idealität), za którym rzeczywistość konsekwentnie i z frustrującą regularnością nie nadąża. A zatem aktywista jest niespokojnym duchem i apologetą w jednym — apologetą świata, który sam wymaga zmiany.

refleksji o życiu społecznym, dostarczają teksty o etnografii krytycznej, krytycznej teorii rasy, krytycznym humanizmie w zbiorze Metody badań jakościowych (red. N.K. Denzin, Y.S. Lincoln, t. 1, Warszawa 2009), a zwłaszcza wprowadzajcy w tę problematykę tekst Egona S. Guby i Yvonny S. Lincoln, Kontrowersje wokól paradygmatów, sprzeczności $i$ wyłaniające się zbieżności, przeł. M. Bobako. Jednym ze spotkanych sposobów opisów pola napięć, jakie tu wchodzą w grę, jest opozycja zaangażowania i izolacji — zob. Zaangażowanie czy izolacja? Wspótczesne strategie społecznej egzystencji humanistów, red. J. Kowalewski, W. Piasek, Olsztyn 2007. Pewną przeciwwagę dla nadmiernego promowania postawy krytycznej i zarazem podkreśleniem odmienności proponowanego podejścią są programy humanistyki afirmatywnej, inni, jak choćby Hal Foster, piszą o Post-krytyczności (przeł. A. Regulska, „Teksty Drugie” 2015, nr 6).

${ }^{8}$ Zob. U. Breuer, Ch. Busch, Kritik/Kritisieren, [w:] Über die Praxis des kulturwissenschaftlichen Arbeitens. Ein Handwörterbuch, Bielefeld 2013, s. 241.

9 R. Konersmann, Kulturoznawstwo a filozofia kultury. Pregnancja kultury, czyli co wtaściwie znaczy to pojęcie?, przeł. K. Krzemieniowa, „Kultura Współczesna” 2009, nr 3. W zredagowanym przez niego Handbuch Kulturphilosophie autorem hasła Kulturwissenschaft jest H. Böhme.

Prace Kulturoznawcze 23, 2019, nr 1

(C) for this edition by CNS 
Aktywistyczne nowe ustanowienie krytyki jest równoznaczne odbudowie fundamentów. Tam, gdzie stara krytyka, działając w duchu Oświecenia, argumentowała oraz szczegółowo rozważała zalety i wady, jej następczyni opiera się na retoryce ${ }^{10}$.

Bardzo przy tym bacznie trzeba wystrzegać się wszelkiej arogancji i przeceniania własnego stanowiska, względem którego należy zastosować podejrzliwość i krytyczność ${ }^{11}$. Retoryczny i perswazyjny, ale w żadnej mierze nie dowolny i nie nieuzasadniany sens mają też sformułowania Konersmanna o „superkrytycznym aktywizmie” i ,funkcjonariuszach niepokoju” (skądinąd odsyła to do Husserlowskiego ujęcia filozofa jako „funkcjonariusza ludzkości”). Ów niepokój, który jest źródłem, przedmiotem i w pewnym sensie celem namysłu nad kulturą, jest w tej koncepcji mocno sprzężony z metaforą kultury jako okrężnej drogi.

\begin{abstract}
Kultura okrężnej drogi (Umwegkultur) to kultura refleksyjna (Reflexionskultur), ale — a to już dostrzegał Seneka — jest i może być to tylko wynikiem kultury niepokoju (Unruhekultur). Podstawowa figura okrężnej drogi powinna być rozumiana jako reakcja na ten początkowy warunek kultury, który nie ma spokoju sam z sobą. Okrężne drogi są przystankiem wśród niepohamowanego zgiełku. Ale także go podsycają, ponieważ sieć okrężnych dróg nigdy nie została ukończona i nigdy nie jest gotowa. A z racji tego, że również kultura okrężnej drogi pozostaje odwiecznym środkiem tymczasowym (Provisorium), domaga się ciągłej uwagi, osądu i krytyki: mądrze wykorzystywanego niepokoju, który jest potrzebny, aby ostatniego słowa nie miał niepokój — nieświadomy i samowystarczalny, zakryty zasłoną normalności ${ }^{12}$.
\end{abstract}

Przywołana koncepcja Konersmanna, której wcale nie trzeba traktować jako wzrocowej i która nie wyczerpuje współczesnego spektrum rozważań o kulturze

${ }^{10}$ R. Konersmann, Wörterbuch der Unruhe, Frankfurt am M. 2015, s. 104-105. To dopełnienie tego, co wcześniej określał jako postrestytucyjną krytykę kultury, która wpisuje się w przejście od Kulturkritk do Kritik der Kultur. Nawiązuję tu do terminologii zastosowanej przez niego we wstępie do zbioru tekstów Kulturkritik (Leipzig 2001). Nota bene, wcześniej Konersmann przygotował podobne opracowanie Kulturphilosophie (Lepizig 1996), ale jeśli wybrano do niego fragmenty prac C. Lévi-Straussa, P. Bourdieu czy C. Geertza, to w Kulturkritik uwzględniono - poza R. Barthes'em - jedynie reprezentantów filozoficznego myślenia o kulturze.

11 Zob. R. Konersmann, Moralna siła poruszającej krytyki kultury, przeł. W. Małecki, „Studia Kulturoznawcze” 2016, nr 1. Temat wiodący całego numeru brzmiał następująco: „Krytyka kultury. Jej istota i formy”. Schwerpunkt drugiego numeru kwartalnika „Zeitschrift für Kulturphilosophie” z roku 2007, pisma, którego Konersmann jest redaktorem naczelnym, stanowiła właśnie „Krytyka kultury". Jako pierwszy został tam zamieszczony artykuł Bollenbocka (Kulturkritik - ein Reflexionsmodus der Moderne), który poddał krytycznej rozwadze dwuznaczną postawę, jaką zajmowali i niekiedy wciąż zajmują krytycy kultury odrzucając akademickie standardy i roszcząc sobie pretensje do społecznego oddziaływania.

12 R. Konersmann, Wörterbuch der Unruhe, Frankfurt am M. 2017, s. 116. Odwołanie w tym cytacie do rzymskiego stoika nie jest przypadkowe. Przywołując w Die Unruhe der Welt (Frankfurt am M. 2015) ten kierunek filozoficzny, Konersamnn dodawał: „Ale Seneka robi decydujący krok dalej, znajdując krytykę kultury jako filozofię kultury, która inaczej niż jedynie oskarżycielska krytyka, rozpoznaje i uznaje kulturę za swój własny świat" (s. 206). Identyfikowanych jako odnoszące się do - nowożytnie się wyrażając - kultury wątków w myśli antycznej dotyczy wspaniała książka Raimara Müllera, Die Entdeckung der Kultur. Antike Theorien über Ursprung und Entwicklung der Kultur von Homer bis Seneca, Düsseldorf-Zürich 2003.

Prace Kulturoznawcze 23, 2019, nr 1

(C) for this edition by CNS 
jako przedmiocie i podmiocie krytyki, bardzo dobrze jednak ilustruje wewnętrzny związek między pojmowaniem kultury i podstawami oraz zadaniami krytyki. Krytyki, która nie tylko czyni kulturę swym przedmiotem, ale dzięki niej jest możliwa i w jej imieniu jest dokonywana.

\section{Bibliografia}

Becker H., Kulturkritik, [w:] Handbuch Kulturphilosophie, red. R. Konersmann, Stuttgart 2012.

Bollenbeck G., Eine Geschichte der Kulturkritik. Von Rousseau bis Günther Anders, München 2007.

Bollenbeck G., Kulturkritik - ein Reflexionsmodus der Moderne, „Zeitschrift für Kulturphilosophie" 2007, nr 2.

Böhme H., Kulturwissenschaft, [w:] Handbuch Kulturphilosophie, red. R. Konersmann, Stuttgart 2012.

Böhme H., Stufen der Reflexion: Die Kulturwissenschaften in der Kultur, [w:] Handbuch der Kulturwissenschaften, red. F. Jaeger, B. Liebsch, t. 2, Stuttgart-Weimar 2011.

Breuer U., Busch Ch., Kritik/Kritisieren, [w:] Über die Praxis des kulturwissenschaftlichen Arbeitens. Ein Handwörterbuch, Bielefeld 2013.

Foster H., Post-krytyczność, przeł. A. Regulska, „Teksty Drugie” 2015, nr 6.

Guba E.S., Lincoln Y.S., Kontrowersje wokót paradygmatów, sprzeczności i wytaniające się zbieżności, przeł. Bobako, [w:] Metody badań jakościowych, red. N.K. Denzin, Y.S. Lincoln, t. 1, Warszawa 2009.

Konersmann R., Krytyka kultury, przeł. K. Krzemienowa, Warszawa 2012.

Konersmann R., Kulturoznawstwo a filozofia kultury. Pregnancja kultury, czyli co właściwie znaczy to pojęcie?, przeł. K. Krzemieniowa, „Kultura Współczesna” 2009, nr 3.

Konersmann R., Moralna siła poruszającej krytyki kultury, przeł. W. Małecki, „Studia Kulturoznawcze" 2016, nr 1.

Konersmann R., Die Unruhe der Welt, Frankfurt am M. 2015.

Konersmann R., Wörterbuch der Unruhe, Frankfurt am M. 2017.

Kulturkritik. Reflexionen in der veränderten Welt, red. R. Konsersmann, Leipzig 2001.

Lachmann H.-J., Vernunftkritik und Kulturkritik. Anmerkungen zu Immanuel Kants Kulturbegriffs. cz. 1, „Kulturwissenschaftliche Studien” 2, 1997; cz. 2, 3, 1998.

Liebert A., Das Problem der Kultur und die Kulturkritik unserer Zeit, „Philosophia” 1936.

Maślanka T., Wiśniewski R., Krytyka jest sprawą każdego z nas, czyli o kulturowym mandaryznizmie Theodora Adorna, [w:] T.W. Adorno, Przemyst kulturalny, przeł. M. Bucholc. Warszawa 2019.

Momoro J., Epistemologia anachronizmu, „Teksty Drugie” 2017, nr 1.

Mucha J., Socjologia jako krytyka społeczna, Warszawa 1986.

Müller R., Die Entdeckung der Kultur. Antike Theorien über Ursprung und Entwicklung der Kultur von Homer bis Seneca, Düsseldorf-Zürich 2003.

Schnädelbach H., Kultura i krytyka kultury, przeł. K. Krzemienowa, [w:] Próba rehabilitacji animal rationale, Warszawa 2001.

Sobrevilla D., Der Ursprung des Kulturbegriffes, der Kulturphilosophie und der Kulturkritik, Tübingen 1971.

Spranger E., Zur geistigen Lage der Gegenwart, [w:] idem, Kulturphilosophie und Kulturkritik, Tübingen 1969.

Zaangażowanie czy izolacja? Wspótczesne strategie społecznej egzystencji humanistów, red. J. Kowalewski, W. Piasek, Olsztyn 2007.

Prace Kulturoznawcze 23, 2019, nr 1

(C) for this edition by CNS 